\title{
A importância do projeto Campanha de Castração na formação do profissional médico veterinário
}

\author{
The importance of the project Castration Campaign for the formation \\ of the veterinarian professional
}

\author{
Carine Budziak $^{[a]}$, Cláudia Turra Pimpão ${ }^{[b]}$, Irmgard Krüger Montoya ${ }^{[c]}$, \\ José Ademar Villanova Júnior ${ }^{[\mathrm{d}]}$, Pricila Flenik de Moraes ${ }^{[\mathrm{e}]}$
}

[a] Médica veterinária, Mestre, Pontifícia Universidade Católica do Paraná (PUCPR), Curitiba, PR - Brasil, e-mail: c_budziak@yahoo.com.br

[b] Médica veterinária, professora Doutora de Farmacologia e Toxicologia Veterinária na Pontifícia Universidade Católica do Paraná (PUCPR), São José dos Pinhais, PR - Brasil, e-mail: claudia.pimpao@pucpr.br

[c] Pedagoga, professora Mestre do curso de Pedagogia na Pontifícia Universidade Católica do Paraná (PUCPR), Curitiba, PR - Brasil, e-mail: irmgard.montoya@uol.com.br

[d] Mestre professor da Pontifícia Universidade Católica do Paraná (PUCPR), Curitiba, PR - Brasil, e-mail: jose.villanova@pucpr.br

[e] Graduada de Medicina Veterinária da Pontifícia Universidade Católica do Paraná (PUCPR), Curitiba, PR - Brasil, e-mail: pricila.flenik@hotmail.com

\section{Resumo}

A extensão universitária proporciona ao aluno graduando a oportunidade de resolução de problemas por meio da interdisciplinaridade, além de vivenciar a prática profissional supervisionado por professores e amparado pela instituição acadêmica, beneficiando a comunidade. O objetivo do trabalho é conhecer as possíveis contribuições do projeto Campanha de Castração para a formação do profissional médico veterinário. A pesquisa foi desenvolvida por meio da aplicação de questionários aos acadêmicos de Medicina Veterinária da PUCPR participantes desse projeto. O estudo demonstrou que, na perspectiva do acadêmico, a participação no projeto contribui para a formação profissional, pois há aplicação dos conceitos teóricos na prática e exercício da interdisciplinaridade. A participação no projeto proporciona ao aluno oportunidade de experimentar e praticar, além de aproximá-lo da realidade, o que contribui para a formação de um profissional mais preparado tecnicamente e para o exercício da cidadania plena. Conclui-se que o presente projeto está inserido em todas as práticas que sustentam a comunidade acadêmica, o meio universitário: ensino, pesquisa e extensão.

Palavras-chave: Extensão universitária. Formação acadêmica. Medicina veterinária. 


\begin{abstract}
The extension education provides students the opportunity to resolve problems through interdisciplinarity and also to experience professional practice, supervised by teachers and supported by the academic institution, benefiting the community. This study aimed at understanding the possible contributions of the project Castration Campaign for the formation of the professional veterinarian. The research was conducted through questionnaires to students of Veterinary Medicine from PUCPR, that had participated in the project. The study showed that, from student's perspective, participating on the project contributes to the training as there are application of theoretical concepts in practice and practice of interdisciplinarity. Participation in the project provides students the opportunity to experience and practice, and bring them to reality, which contributes to the formation of a more technically prepared professional and for the exercise of full citizenship. The paper concludes that this project is embedded in all practices that support the academic community: teaching, research and extension.
\end{abstract}

Keywords: University extension. Education. Veterinary medicine.

\title{
Introdução
}

A Organização Mundial da Saúde (OMS) vem alertando os governos a respeito do aumento populacional de cães no mundo nos últimos anos. Segundo dados da OMS, a população mundial de cães em 2003 estava em torno de 600 milhões, número que pode dobrar em dez anos (JORNAL CORREIO DO BRASIL, 2003).

De acordo com dados da Associação Nacional de Fabricantes de Alimentos para Animais (ANFAL Pet), atualmente há 32 milhões de cães no Brasil (NUNES; CESÁRIO, 2009). No ano de 2002, o número de cães em Curitiba era de aproximadamente 240 mil, sendo que destes, 120 mil estavam nas ruas (JORNAL O ESTADO DO PARANÁ, 2003). Segundo o censo canino realizado por amostragem em Curitiba no ano de 2007, verificou-se que a proporção média de pessoa/cão é de aproximadamente 4:1, ou seja, quatro pessoas para cada cão. Sendo assim, em Curitiba são cerca de 1,8 milhões de habitantes, com uma população de 450 mil cães (BIONDO et al., 2007).

Segundo a International Companion Animal Management Coalition (2007), alguns membros das autoridades públicas e governamentais estão preocupados com problemas de saúde pública e segurança associados à população de cães perambulantes, incluindo a transmissão de doenças a humanos (zoonoses) e a outros animais, injúrias e o medo causados por comportamento agressivo, perturbações por barulho e sujeira, predação animal e causas de acidentes de trânsito. A partir disso, podemos perceber a importância do controle populacional de cães e seu impacto na melhora relativa aos aspectos de saúde pública. Alguns cães errantes são recolhidos por proprietários de abrigos que objetivam cuidar e oferecer melhores condições de vida a esses animais. A castração é de grande importância, pois ocorre o controle populacional dentro dos abrigos e, além disso, os animais castrados são adotados com maior facilidade. Vale lembrar que este método controla a população dos cães de forma eficiente, uma vez que após a realização da cirurgia não há a menor possibilidade de fêmeas castradas ficarem prenhas e de machos castrados fertilizarem fêmeas eventualmente não castradas.

O curso de Medicina Veterinária da PUCPR desenvolveu um projeto de campanha de castração em parceria com uma organização não governamental denominada Associação São Francisco de Assis de Proteção aos Animais. A Campanha de Castração é um projeto desenvolvido com objetivo de esterilização de animais de abrigo e também de proporcionar ao aluno uma vivência prática do profissional médico veterinário. Neste sentido, a equipe de alunos torna-se responsável pelo seu paciente, porém, em todo processo é supervisionado por uma equipe composta por professores, médicos veterinários residentes e mestrandos.

O aluno participante constrói o seu conhecimento a partir da vivência do processo, pois ele necessita da aplicação de vários conceitos de diversas disciplinas para o entendimento do projeto como um todo. O ensino constitui a função mais evidente na maior parte das universidades, instituições nas quais se adquire o conhecimento especializado. Mas além do ensino, as universidades devem promover também a pesquisa e 
a extensão. Porém, a pesquisa, para ser realmente válida, não deve ser meramente técnica, e sim trazer aplicabilidade e benefícios à comunidade na qual está inserida. A caminhada do acadêmico dentro da universidade deve contemplar essas áreas, pois para uma formação profissional mais completa o acadêmico deve saber aplicar os conceitos teóricos adquiridos na prática profissional. Além disso, sua atuação deve ser realizada de forma ética, promovendo benefícios para a comunidade.

A Pontifícia Universidade Católica do Paraná, como universidade comunitária e confessional, procura conformar os procedimentos institucionais com a moral cristã e, neste contexto, desenvolve suas atividades procurando atender aos objetivos de interesse social em benefício da comunidade. Cumpre, dessa forma, o papel de agente integrador do conhecimento técnico-científico em prol do progresso e do desenvolvimento da sociedade (MOREIRA, 2004). A Pró-Reitoria Comunitária e de Extensão da PUCPR tem a missão de articular esses processos de parcerias entre a sociedade e universidade (MOREIRA, 2004). Juliatto (2003) justifica isso afirmando que "a Universidade tem que estar perto do barulho da rua". Extensão universitária para a PUCPR pode ser entendida, fundamentalmente, como uma atitude de abertura da instituição para a comunidade. Moreira (2004, p. 42) afirma que "esta prática pretende elevar o padrão de vida social, cultural, intelectual e espiritual da população, bem como propiciar aos estudantes aplicações dos conhecimentos teóricos adquiridos em realidades concretas".

A possibilidade de implementação de atividades que se viabilizam pelo apoio institucional irrestrito faz com que a extensão universitária tenha relevância para a formação acadêmica dos alunos do curso de Medicina Veterinária da PUCPR. A participação das atividades de extensão promove a formação acadêmica e humana dos alunos e professores participantes das atividades e, além disso, elevam o padrão de vida da população carente, pois há a promoção da saúde humana por meio da promoção da saúde animal (MOREIRA, 2004).

As contribuições de caráter técnico desenvolvidas por meio das atividades de extensão realizadas durante o curso de graduação de Medicina Veterinária possibilitam ao aluno vivenciar e participar das condições reais da sua futura profissão e aplicar os conhecimentos que lhes são apresentados pela universidade nas atividades formais que compõem o currículo do curso de graduação (MOREIRA, 2004).

A extensão universitária é capaz de proporcionar essa vivência ao aluno por meio da interdisciplinaridade para resolução de problemas, bem como dá oportunidade para o aluno vivenciar a prática profissional, supervisionado por professores e amparado pela instituição acadêmica.

O projeto Campanha de Castração oferece ao acadêmico de Medicina Veterinária a oportunidade de aplicar na prática os conhecimentos teóricos adquiridos. Além da participação dos alunos de graduação, este projeto permite a inserção de alunos de pós-graduação (residência médica e mestrado). O número de cães participantes e o volume de exames laboratoriais e clínicos que são realizados são uma fonte enorme de dados gerados. Esses dados podem ser uma fonte de pesquisa tanto ao aluno graduando participante de iniciação científica, quanto ao aluno de pós-graduação.

O aluno que participa de um projeto de extensão visualiza a importância da atuação da universidade em benefício da comunidade. Esse tipo de atividade pode promover a formação de um profissional preparado tecnicamente, como também de um profissional cidadão.

O objetivo do presente trabalho é conhecer as possíveis contribuições do projeto Campanha de Castração para a formação do profissional médico veterinário.

\section{Materiais e métodos}

\section{Caracterização da pesquisa}

A investigação do problema de pesquisa ocorreu por meio do método de estudo de caso. Um estudo classificado como qualitativo, pois se desenvolve numa situação natural, é rico em dados descritivos, tem um plano aberto e flexível e focaliza a realidade de forma complexa e contextualizada (LÜDKE; ANDRÉ; 1986).

A pesquisa qualitativa tem o ambiente natural como sua fonte direta de dados e o pesquisador como seu principal instrumento. Os dados coletados são predominantemente descritivos e a análise tende a seguir 
um processo indutivo. Além disso, o pesquisador se preocupa em retratar a perspectiva dos participantes e enfatiza mais o processo que o produto (LÜDKE; ANDRÉ, 1986).

Os investigadores qualitativos estabelecem estratégias e procedimentos que lhes permitam tomar em consideração as experiências do ponto de vista do informador. O processo de condução de investigação qualitativa reflete uma espécie de diálogo entre os investigadores e os respectivos sujeitos, uma vez que estes não são abordados por aqueles de uma forma neutra (BOGDAN; BIKLEN, 1994).

\section{Instrumentos de pesquisa}

A pesquisa foi desenvolvida por meio da aplicação de questionários aos alunos participantes do projeto campanha de castração.

Segundo Marconi e Lakatos (2002), o questionário é um instrumento de coleta de dados que possui uma série ordenada de perguntas. Estas perguntas deverão ser respondidas por escrito e sem a presença do pesquisador. Dentre as principais vantagens da aplicação do questionário descritas por Marconi e Lakatos (2002) estão:

- economia de tempo, viagens e obtenção de grande número de dados;

- atingir o maior número de pessoas simultaneamente;

- abranger área geográfica mais ampla;

- economia de pessoal;

- obter respostas mais rápidas e mais precisas;

- maior liberdade nas respostas, em razão do anonimato;

- mais segurança, pelo fato de as respostas não serem identificadas;

- menos riscos de distorção, pela não influência do pesquisador;

- mais tempo para responder e em hora mais favorável;

- mais uniformidade na avaliação, em virtude da natureza impessoal do instrumento;

- obter respostas que materialmente seriam inacessíveis.

E as desvantagens são (MARCONI; LAKATOS, 2002):

- percentagem pequena dos questionários que voltam;

- grande número de perguntas sem respostas;

- impossibilidade de ajudar o informante em questões mal compreendidas;

- a dificuldade de compreensão, por parte dos informantes, leva a uma uniformidade aparente;

- na leitura de todas as perguntas, antes de respondê-las, pode uma questão influenciar a outra;

- a devolução tardia prejudica o calendário ou sua utilização;

- o desconhecimento das circunstâncias em que foram preenchidos torna difícil o controle e a verificação;

- exigência de um universo mais homogêneo.

A maioria das pessoas possui certa aversão a papéis (excesso de burocracia). Assim, o questionário, pela forma como muitas vezes é empregado, leva a esta conotação. Porém, quando bem elaborado, este instrumento desperta os respondentes de forma a motivá-los a participar da pesquisa e interessar-se pelos seus resultados (LABES, 1998).

\section{Universo da pesquisa}

A pesquisa foi realizada durante o período de atividades do projeto campanha de castração. A população de estudo foram os acadêmicos de Medicina Veterinária participantes do projeto. As Campanhas de Castração fazem parte do Projeto Comunitário, um programa institucional que está inserido dentro da matriz 
curricular de todos os cursos da universidade. Foram realizadas 17 Campanhas de Castração durante o período compreendido entre 17 de abril de 2008 e 18 de junho de 2009. Todos os procedimentos cirúrgicos foram realizados no Laboratório de Técnica Operatória do curso de Medicina Veterinária da PUCPR, câmpus São José dos Pinhais.

Os organizadores do projeto possuem cadastro dos alunos participantes contendo informações como nome, matrícula, telefone, e-mail, entre outras. A partir desse cadastro foi possível o contato com a população de estudo. Os instrumentos de pesquisa foram enviados por e-mail. Os acadêmicos tinham um prazo de 15 dias para devolver os questionários respondidos. Este questionário possuía perguntas abertas, fechadas e de múltipla escolha, visando a detectar possíveis contribuições do projeto Campanha de Castração para a formação acadêmica.

\section{Resultados}

A elaboração do questionário foi realizada por meio eletrônico em um site (Google docs) que disponibiliza gratuitamente ferramentas para elaboração de perguntas abertas, fechadas, de múltipla escolha, entre outras. Além disso, as respostas enviadas são automaticamente inseridas em um banco de dados, o qual pode ser exportado, por exemplo, para o Excel. O contato com os alunos para entrega do questionário foi realizado pelo envio de e-mail. Por meio deste, explicou-se a importância da pesquisa e solicitou-se o preenchimento do questionário. Os alunos responderam ao questionário acessando o link fornecido no e-mail. Os questionários foram enviados a 89 alunos participantes do projeto Campanha de Castração. Dez e-mails não chegaram ao destino, pois as caixas de mensagens estavam lotadas. Catorze questionários foram respondidos, representando 18\% de devolução. Segundo Marconi e Lakatos (2002), em média os questionários expedidos pelo pesquisador alcançam 25\% de devolução. Pode-se considerar que a média de devolução alcançada (18\%) está abaixo do esperado (25\%), porém o período de envio dos questionários coincidiu com a época de realização de provas finais e término do semestre. Isto pode justificar a baixa devolutiva e sugere que os questionários devem ser enviados antes do referido período.

Os alunos participantes do projeto Campanha de Castração possuem idade entre 21 e 40 anos, com uma média de 24,57 anos e 5,47 de desvio padrão. Considerando o sexo, 87,5\% dos alunos são mulheres e $12,5 \%$ são homens. A maioria dos alunos que responderam o questionário estava cursando o oitavo período (42,86\%), mas também houve a participação de alunos de outros períodos: terceiro (21,43\%), segundo $(14,28 \%)$, primeiro, quinto e sexto $(7,14 \%)$.

$\mathrm{Na}$ análise da questão sobre a importância da participação na Campanha de Castração, 100\% dos alunos concordam que a sua participação pode contribuir para a sua formação como profissional médico veterinário. E alguns alunos justificam: "Pudemos colocar em prática realmente o que vimos em sala de aula, o que, muitas vezes, não poderia ser realizado em estágios, pois, dependendo do local, ficávamos somente olhando/auxiliando e não realizando a cirurgia". E outro acrescenta: "Oportunidade de servir, aprendizado prático, aplicação de conhecimentos teóricos, a campanha tem um ritmo de trabalho bem intenso, favorecendo o aprendizado". Outro aluno comenta a importância da participação na campanha e relaciona a sua escolha profissional: "participar da prática cirúrgica faz. com que se tenha ideia da realidade que será enfrentada, da responsabilidade com o paciente e da conduta clínica; e fer com que eu tivesse certeza da profissão que escolhi”. Além disso, um aluno enfatiza a oportunidade de praticar e aprender com animais vivos:

[...] realizar cirurgia em animais vivos é essencial para a formação de um médico veterinário, além das práticas com anestesia e procedimentos simples como aplicação de medicamentos, exame clinico, fixação de cateter e outros, que não épossivel realizar em sala.

Em relação às questões a respeito da aplicação dos conteúdos aprendidos em sala de aula e sobre a interdisciplinaridade, $100 \%$ dos alunos responderam que no projeto Campanha de Castração há aplicação dos conceitos teóricos na prática e há o exercício da interdisciplinaridade. Um aluno exemplifica:

Rev. Acad., Ciênc. Agrár. Ambient., Curitiba, v. 8, n. 3, p. 361-370, jul./set. 2010 
Pude praticar a técnica de cirurgia, assim como desenvolver meus conhecimentos em clínica (pós-operatório, importância da castração, doenças envolvidas) e ainda ter experiência com anestesiologia. Além de tudo isso, o contato com os animais e a prática de contenção, aplicação de medicamentos, entubar e canular veia, entre outras atividades desenvolvidas na campanha.

E outro acrescenta: "avaliação de exames pré-operatórios, avaliação clínica do paciente; o próprio ato cirúrgico e pós-operatório, todos interligados, caracterizando a interdisciplinariedade". Um aluno comenta seu ponto de vista sobre a interdisciplinaridade: "podemos vivenciar situações de emergência, práticas de anestesia e clínica médica. Notamos as limitações e como contorná-las".

As disciplinas mais citadas como pré-requisito para participação da campanha de castração foram: Anatomia, Técnica Cirúrgica, Anestesiologia, Farmacologia e Clínica de Pequenos Animais.

Com relação aos motivos para a participação do projeto, $35 \%$ dos alunos entraram com o objetivo de vivenciar a prática do médico veterinário; $28 \%$ responderam cumprir o projeto comunitário; outros 28\% para aprender a técnica cirúrgica e anestésica, e 7\% escolheram outro motivo e justificaram: "[...] acrescento ainda a necessidade de medidas de controle populacional, em benefício social aos proprietários carentes, contribuindo assim contra o abandono de cães e gatos nas ruas". Cem por cento dos alunos recomendariam a um colega a participação no projeto Campanha de Castração. E há várias justificativas:

Importante etapa na formação de médico veterinário, pois proporciona vivência da prática cirúrgica, cuidados pós-operatórios, avaliação pré-operatória, avaliação clínica do paciente, interação com outros colegas e possibilidade de compartilhar conhecimentos, além da contribuição social que se realiza numa campanha como esta.

Outros alunos acrescentam: "Oportunidade única de vivenciar intensamente a rotina cirúrgica."; "Por ser uma atividade completa, que atua em várias áreas da medicina de pequenos animais"; "A prática é necessária para fixar os conhecimentos e aprender a lidar com situações que não estamos preparados".

Os alunos percebem que o projeto traz benefícios à comunidade e comentam: "Ajuda a reduحir o número de animais abandonados, proporciona aos proprietários menos abastados a possibilidade da castração com cuidados e responsabilidade porparte dos acadêmicos e professores"; "Colabora com os abrigos de proteção e proprietários carentes, pois estes não dispõem de recursos para esse tipo de procedimento, além do fato de corrigir outras alterações que se fazem presentes, descobertas durante a etapa pré-operatória". Nesse caso, o aluno comenta que, além das cirurgias de castração, quando há presença de doença ou anormalidade concomitante, o animal é encaminhado para tratamento, o qual é realizado por profissionais da Unidade Hospitalar de Animais de Companhia PUCPR. Um aluno ainda sugere que as castrações, além de serem realizadas em animais de proprietários carentes, deveriam ser realizadas em cães errantes: "... acho que deveríamos fazer isso com os animais de rua também, pois com certeza a superpopulação de cães e gatos errantes é um problema de Saúde Pública".

Quando perguntados se a disciplina de Saúde Pública está relacionada ao projeto Campanha de Castração, 92,86\% dos alunos responderam sim e um aluno comenta "[...] mas não é muito mencionada depois que se começa a campanha, poderia melhorar". Apenas 7,14\% dos alunos acreditam que a disciplina de Saúde Pública não está relacionada ao projeto campanha de castração.

Dentre as sugestões mais indicadas pelos alunos estão:

- maior cobrança pelo comprometimento dos alunos envolvidos;

- melhorar organização das etapas da campanha de castração (períodos pré, trans e pós-operatórios);

- aumentar o número de animais beneficiados;

- aumentar a frequência da realização das campanhas;

- realizar parcerias com os Centros de Controle de Zoonoses.

Como as atividades do projeto de campanha de castração estão no início, obviamente há muitos pontos a serem revistos e reestruturados. Todas as sugestões são extremamente pertinentes e levam à reflexão para que as próximas campanhas ocorram cada vez melhor.

Rev. Acad., Ciênc. Agrár. Ambient., Curitiba, v. 8, n. 3, p. 361-370, jul./set. 2010 


\section{Discussão}

Segundo Lei das Diretrizes e Bases da Educação Nacional - LDB, n. 9.394/96 (BRASIL, 1996), o ensino superior tem por finalidade o pleno desenvolvimento do educando, seu preparo para o exercício da cidadania e sua qualificação para o trabalho, além de estimular a criação cultural e o desenvolvimento do espírito científico e do pensamento reflexivo, e incentivar o trabalho de pesquisa e investigação científica, visando ao desenvolvimento da ciência e da tecnologia e da criação e difusão da cultura. Desse modo, busca-se desenvolver o entendimento do homem e do meio em que ele vive, além de promover a divulgação de conhecimentos culturais, científicos e técnicos que constituem patrimônio da humanidade e comunicar o saber por meio do ensino, de publicações ou de outras formas de comunicação (CAMILO; RIBAS, 2007).

O ensino superior é responsável pela formação do aluno em todas as áreas do conhecimento, e é durante os anos de graduação, nas aulas práticas e teóricas, com participação em projetos de pesquisa, elaboração de trabalhos monográficos, estudos individuais e em grupos, etc., que se constroem bons profissionais (CAMILO; RIBAS, 2007).

A conquista da interdisciplinaridade entre ensino, pesquisa e extensão representa hoje um dos maiores desafios das universidades brasileiras (SILVA; VASCONCELOS, 2006).

A extensão, entendida como processo educativo, cultural e científico, articula-se com o ensino e a pesquisa de forma indissociável, ao mesmo tempo em que reforça a realização do papel social da universidade e contribui para a sua transformação, como também da sociedade. Daí por que um importante objetivo da extensão deve ser a efetivação de uma prática acadêmica que vincule ensino e pesquisa às demandas da sociedade (ENCONTRO NACIONAL DE UNIVERSIDADES, 1999). Dessa forma, a extensão é entendida como uma prática social de construção de conhecimento e de desenvolvimento de aprendizagens significativas, sem o que se descaracteriza e se transforma em assistencialismo ou venda de serviços (JULIATTO, 2005).

A Extensão é uma via de mão-dupla, com trânsito assegurado à comunidade acadêmica, que encontrará, na sociedade, a oportunidade de elaboração da práxis de um conhecimento acadêmico. No retorno à universidade, docentes e discentes trarão um aprendizado que, submetido à reflexão teórica, será acrescido àquele conhecimento (FÓRUM DE PRÓ-REITORES DE EXTENSÃO, 2000).

A revalorização da extensão não é alheia às atualizações na formação acadêmica, pois, como defende Jezine (2004),

a nova visão de extensão universitária passa a se constituir parte integrante da dinâmica pedagógica curricular do processo de formação e produção do conhecimento, envolvendo professores e alunos de forma dialógica, promovendo a alteração da estrutura rígida dos cursos para uma flexibilidade curricular que possibilite a formação crítica.

Percebe-se, com isso, que a formação do aluno vai além da aquisição de conhecimentos técnicocientíficos, até porque esses se esvaziam quando não integrados à realidade. Para uma abordagem inovadora, a aprendizagem deve ir além da aplicação imediata, impulsionando o sujeito a criar e responder a desafios, a ser capaz de gerar tecnologias e de manter a habilidade de aprender e recriar permanentemente; ou seja, a graduação deve se transformar no lócus de construção/produção do conhecimento, em que o aluno atue como sujeito da aprendizagem (SILVA; VASCONCELOS, 2006).

Segundo Morgado e Galzerano (2007), o professor da área agrária, incluindo Medicina Veterinária, tem a possibilidade de realizar aulas práticas interagindo com animais, o que possibilita uma facilidade na comunicação na prática do aprender fazendo. Quando há essa possibilidade de aliar a teoria e a prática, o aprendizado torna-se mais interessante. A campanha de castração é um exemplo, pois o aluno acompanha a preparação do paciente no pré-operatório, como o exame clínico e a coleta de amostras para exames laboratoriais, realiza o procedimento cirúrgico e libera seu paciente após a recuperação anestésica.

Matera (2008) comenta que durante as aulas teóricas e práticas é ensinado conhecimento, atitudes e habilidades, porém é no centro cirúrgico que os alunos aprendem "a unir tudo" nas diferentes circunstâncias, como ocorre na prática. Esse modo de aprendizado é um exemplo da aplicação do conceito de 
interdisciplinaridade, pois o aluno deve dominar conceitos de diversas disciplinas para realizar a atividade e, como consequência, construir seu conhecimento.

Segundo Nogueira (1998, apud PINHEIRO, 2002, p. 44), "interdisciplinaridade é o trabalho de integração das diferentes áreas do conhecimento. Um real trabalho de cooperação e troca, aberto ao diálogo e ao planejamento”. Essa interdisciplinaridade, vista como uma questão de vida prática, diária, não aborda uma disciplina tradicional. $\mathrm{O}$ aluno vivencia e compreende a realidade a que pertence. Além disso, oferece uma nova interação como forma de investigação sobre o que interessa ao próprio estudante (PINHEIRO, 2002).

Pinheiro (2002) define: "o aluno do ensino interdisciplinar tem capacidade para solucionar problemas que ultrapassem os limites de uma disciplina, sua visão do mundo é globalizada e, em seu pensamento, as matérias são interligadas."

A proposta interdisciplinar é indispensável para se aplicar no processo de educação na sociedade atual, pois dela pode-se desvelar ao homem a visão da totalidade, além de desenvolver o espírito crítico e criativo por meio das atividades cotidianas desenvolvidas numa escola, para nelas perceber a multiplicidade de relações entre as disciplinas, pensamento, sentimento, valores e aprimorá-los, a fim de superar e ultrapassar contradições e diferenças (FANFARRÃO; ARAÚJO, 2004).

O fluxo, que estabelece a troca de saberes sistematizados, acadêmico e popular, tem como consequências a produção do conhecimento resultante do confronto com a realidade brasileira e regional, a democratização do conhecimento acadêmico e a participação efetiva da comunidade na atuação da universidade. Além de instrumentalizadora deste processo dialético de teoria/prática, a extensão é um trabalho interdisciplinar que favorece a visão integrada do social (FÓRUM DE PRÓ-REITORES DE EXTENSÃO, 2000).

O caminho interdisciplinar é amplo no seu contexto e nos revela um quadro que precisa ser redefinido e ampliado. Tal constatação induz-nos a refletir sobre a necessidade de professores e alunos trabalharem unidos, se conhecerem e se entrosarem, para juntos vivenciarem uma ação educativa mais produtiva. O papel do professor é fundamental no avanço construtivo do aluno. É ele, o professor, quem pode captar as necessidades do aluno e o que a educação lhe proporcionar. A interdisciplinaridade do professor pode envolver e modificar o aluno quando ele assim o permitir (TAVARES, 1999).

Moreira (2004) comenta que a participação em um programa de extensão universitária possibilita ao aluno vivenciar a interdisciplinaridade, aplicando os conceitos teóricos adquiridos na prática. A extensão universitária pode oferecer possibilidades para o professor exercer sua professoralidade e pessoalidade, como sugere Pereira (1996). Na professoralidade e na pessoalidade estão incluídas também as experiências pessoais e profissionais de cada um (EGGERT-STEINDEL, 2002).

A sociedade atual exige que a universidade não somente capacite os acadêmicos para futuras habilitações nas especializações tradicionais, mas principalmente que tenha em vista a formação deles, para desenvolver suas competências e habilidades em função de novos saberes que se produzem e que exigem um novo tipo de profissional (FANFARRÃO; ARAÚJO, 2004).

No ensino superior, a falta de contato do conhecimento com a realidade parece ser uma característica bastante acentuada. Os professores, no esforço de levar seus alunos a aprender, fazem-no de maneira a dar importância ao conteúdo em si, e não à sua interligação com a situação da qual emerge, gerando, assim, a clássica dissociação entre teoria e prática (FANFARRÃO; ARAÚJO, 2004). O Fórum de Pró-Reitores das Universidades Públicas Brasileiras defende que na formação do profissional é imprescindível sua interação com a sociedade para situá-lo historicamente, identificá-lo culturalmente e referenciar a sua formação técnica à realidade (SILVA; VASCONCELOS, 2006).

A educação deve ser entendida e trabalhada de forma interdisciplinar, na qual o aluno é agente ativo, comprometido, responsável, capaz de planejar suas ações, assumir responsabilidades, tomar atitudes diante dos fatos e interagir no meio em que vive, contribuindo, desta forma, para a melhoria do processo ensinoaprendizagem. Assim sendo, é de responsabilidade dos professores fazer com que o aluno seja sujeito de sua aprendizagem, ciente do que irá realizar, como e para quê, ou seja, levar o aluno a aprender a planejar, a trabalhar com hipóteses e a encontrar soluções. Nessa perspectiva, para que ele adquira essas habilidades, faz-se necessário trabalhar com práticas pedagógicas voltadas para sua formação, para o exercício da cidadania plena, respeitando a individualidade de cada um, utilizando-se de conteúdos interdisciplinares e contextualizados. Vale lembrar que 
a questão interdisciplinar emerge como orientação da superação da dicotomia entre pedagogia e epistemologia, entre ensino e produção de conhecimentos científicos, daí porque a sua maior complexidade e necessidade de superação da perspectiva departamental e setorizada do ensino (FANFARRÃO; ARAÚJO, 2004).

\section{Considerações finais}

Com a presente pesquisa foi possível observar a importância da Campanha de Castração na formação do profissional médico veterinário, pois a participação nesse projeto traz a oportunidade ao aluno de praticar, experimentar e também de errar. Com isso, o acadêmico torna-se mais seguro para tomadas de decisões na sua prática profissional.

O projeto de extensão é capaz de proporcionar ao aluno a visão da totalidade, aprender sobre os conceitos de interdisciplinaridade, e de conhecer de fato a realidade do profissional.

Nesse sentido, a participação dos alunos no projeto complementa os conteúdos curriculares que são vistos em sala de aula e aproxima a teoria da prática. O processo ensino-aprendizagem é facilitado, o aluno torna-se sujeito de sua aprendizagem e desenvolve o seu espírito crítico e criativo.

A aproximação da universidade e comunidade propicia ao aluno oportunidade do exercício da cidadania plena. O profissional formado sob estes princípios torna-se completo, uma vez que está preparado tecnicamente e também como cidadão.

A campanha de castração proporcionou ao acadêmico de Medicina Veterinária aplicação prática de seus conhecimentos, o exercício da interdisciplinaridade e também demonstrou a importância da atuação de um projeto de pesquisa em benefício da comunidade. A partir disso, entende-se que o presente trabalho está inserido em todas as práticas que sustentam a comunidade acadêmica e o meio universitário: ensino, pesquisa e extensão.

\section{Referências}

AUMENTO da população de cães no mundo ameaça saúde pública. Jornal Correio do Brasil, 3 set. 2003. Disponível em: <http://www.correiodobrasil.com.br/noticia.asp?c=27619>. Acesso em: 7 jul. 2009.

BIONDO, A. W. et al. Carrocinha não resolve. Revista Conselho Regional de Medicina Veterinária - Paraná, n. 25, p. 20-21, out./dez. 2007.

BOGDAN, R.; BIKLEN, S. Investigação qualitativa em educação: uma introdução à teoria e aos métodos. Portugal: Porto, 1994.

BRASIL. Lei n. 9.394/96, de 20 de dezembro de 1996. Estabelece as diretrizes e bases da educação nacional. Diário Oficial [da] República Federativa do Brasil, Poder Legislativo, Brasília, DF, 23 dez. 1996. p. 27833. Disponível em:<http://www6.senado.gov.br/legislacao/ListaTextoIntegral.action?id=75723>. Acesso em: 23 jul. 2009.

CAMILO, M.; RIBAS, K. M. F. Formação docente: professor universitário na atualidade. Revista Eletrônica Lato Sensu, Ano 2, n. 1, 2007. Disponível em: < http://web03.unicentro.br/especializacao/Revista_Pos/P\%C3\%A1ginas/2\%20 Edi\%C3\%A7\%C3\%A3o/Humanas/PDF/5-Ed2_CH-ForDoce.pdf>. Acesso em: 14 dez. 2009.

CAMPANHA tenta reduzir número de cães nas ruas. Jornal O Estado do Paraná, 15 ago. 2003. Disponível em: http://www.parana-online.com.br/editoria/cidades/news/56440/?noticia=CAMPANHA+TENTA+REDUZIR+ NUMERO+DE+CAES+NAS+RUAS>. Acesso em: 7 jul. 2009.

EGGERT-STEINDEL, G. A extensão universitária uma contribuição na atuação da docência em biblioteconomia e documentação: um relato. Revista ACB: Biblioteconomia em Santa Catarina, v. 7, n. 1, p 51-58, 2002.

ENCONTRO NACIONAL DE UNIVERSIDADES. Políticas e ações de extensão universitária para a promoção dos direitos da infância e da adolescência: relatório. Belo Horizonte: PUC Minas, 1999. 
FANFARRÃO, N. R. L.; ARAÚJO, C. S. A. Importância da interdisciplinaridade no ensino superior. Educere: Revista da Educação, v. 4, n. 2, p. 103-115, 2004.

FÓRUM DE PRÓ-REITORES DE EXTENSÃO DAS UNIVERSIDADES PÚBLICAS BRASILEIRAS. Plano Nacional de Extensão Universitária. Brasília: UnB; CEAD, 2000.

INTERNATIONALCOMPANION ANIMAL MANAGEMENT COALITION -ICAM. Humane dog population management guidance. London: United Kingdon, 2007.

JEZINE, E. As práticas curriculares da extensão universitária. In: CONGRESSO BRASILEIRO DE EXTENSÃO UNIVERSITÁRIA, Reconhecer diferenças construir resultados, 2., 2004, Belo Horizonte. Anais... Brasília: Unesco, 2004. p. 332-339. Disponível em: <http://www.ufmg.br/congrext/Gestao/Gestao12.pdf>. Acesso em: 20 dez. 2009.

JULIATTO, C. I. Educação e extensão a serviço das pessoas e da comunidade. Gazeta do Povo, Opinião, Curitiba, 26 set. 2003.

JULIATTO, C. I. Um jeito próprio de servir: portas abertas para a comunidade. Curitiba: Champagnat, 2005.

LABES, E. M. Questionário: do planejamento à aplicação na pesquisa. Chapecó: Grifos, 1998.

LÜDKE, M.; ANDRÉ, M. E. D. A. Pesquisa em educação: abordagens qualitativas. São Paulo: Editora Pedagógica e Universitária, 1986.

MARCONI, M. de A.; LAKATOS, E. M. Técnicas de pesquisa. 5. ed. São Paulo: Atlas, 2002.

MATERA, J. M. O ensino de cirurgia: da teoria à prática. Ciência Veterinária Tropical, v. 11, p. 96-101, 2008. Suplemento 1.

MOREIRA, J. L. Extensão universitária: uma análise da experiência do curso de Medicina Veterinária da PUCPR. 2004. 119 f. Dissertação (Mestrado em Educação) - Pontificia Universidade Católica do Paraná, Curitiba, 2004.

MORGADO, E.; GALZERANO, L. Relações entre professor-aluno para um melhor ensino-aprendizagem das ciências agrárias. Redvet: Revista Eletrônica de Veterinária, v. 8, n. 1, 2007. Disponível em: <http://www.veterinaria.org/ revistas/redvet/n010107/010704.pdf>. Acesso em: 14 jul. 2009.

NUNES, L.; CESÁRIO, S. Linha Guabi marca presença na segunda maior feira do mundo no seguimento pet. Disponível em: $<$ http://www.agroagenda.com.br/noticias/detalhe_ult_not.asp?noticia=31699>. Acesso em: 8 jul. 2009

PEREIRA, M. V. A estética da professoralidade: um estudo interdisciplinar sobre a subjetividade do professor. 1996. 198 f. Tese (Doutorado em Educação) - Departamento de Educação, Pontifícia Universidade Católica de São Paulo, São Paulo, 1996.

PINHEIRO, E. J. O ensino interdisciplinar. Sciencia Vila Velha (ES), v. 3, n. 2, p. 39-50, jul/dez. 2002.

SILVA, M. S.; VASCONCELOS, S. D. Extensão universitária e formação profissional: avaliação da experiência das ciências biológicas na Universidade Federal de Pernambuco. Estudos em Avaliação Educacional, v. 33, n. 17, p. 119-135, 2006.

TAVARES, D. E. Aspectos da história deste livro. In: FAZENDA, I. Práticas interdisciplinares na escola. São Paulo: Cortez, 1999.

Recebido: 23/06/2009

Received: 06/23/2009

Aprovado: $12 / 05 / 2010$

Approved: 05/12/2010

Rev. Acad., Ciênc. Agrár. Ambient., Curitiba, v. 8, n. 3, p. 361-370, jul./set. 2010 